\title{
Desenvolvendo e Descobrindo Competências no Currículo Escolar por meio do Raciocínio Computacional
}

\author{
Ecivaldo de Souza Matos \\ Onda Digital/IME/UFBA \\ Universidade Federal da Bahia \\ Salvador - Brasil \\ ecivaldo@ufba.br \\ Juliana M. O. dos Santos \\ Onda Digital/IME/UFBA \\ Universidade Federal da Bahia \\ Salvador - Brasil \\ juliana.maria@ufba.br
}

\author{
Cláudia Borges Coutinho \\ Onda Digital/IME/UFBA \\ Colégio Estadual Góes Calmon \\ Salvador - Brasil \\ claudiabcout@gmail.com \\ Leonardo R. de Azevedo \\ Onda Digital/IME/UFBA \\ Universidade Federal da Bahia \\ Salvador - Brasil \\ leonardo.azevedo@ufba.br \\ Diego Zabot \\ Onda Digital/IME/UFBA \\ Universidade Federal da Bahia \\ Salvador - Brasil \\ diego.zabot@ufba.br
}

\author{
Euma Silva Santos \\ Onda Digital/IME/UFBA \\ Universidade Federal da Bahia \\ Salvador - Brasil \\ euma.silva@ufba.br \\ Gracielle O. Tavares \\ Onda Digital/IME/UFBA \\ Universidade Federal da Bahia \\ Salvador - Brasil \\ gracielle.oliveira@ufba.br
}

\section{RESUMO}

A universidade, enquanto espaço de desenvolvimento, produção e compartilhamento de conhecimentos tem procurado se posicionar perante a realidade e prover ações formativas pertinentes às exigências dos sistemas educacionais e sociais da contemporaneidade. Neste artigo relatamos a experiência vivenciada durante as atividades de intervenções realizadas em um curso de formação continuada de professores para apropriação didática do Raciocínio Computacional. Por meio de experimentações didáticas, foram discutidas questões conceituais relacionadas às habilidades do Raciocínio Computacional para o desenvolvimento de competências curriculares. As atividades foram semipresenciais, com uso de metodologias ativas e diferentes recursos midiáticos.

\section{PALAVRAS-CHAVE}

Formação de Professores, Raciocínio Computacional, Pensamento Computacional.

\section{Introdução}

Os indivíduos são desafiados todo tempo a compreender situações e resolver problemas complexos; isso exige habilidades que permitam relacionar conceitos, categorias e valores de diferentes naturezas e áreas de conhecimento, ou seja, habilidades interdisciplinares. A universidade e a escola, enquanto espaços de

\footnotetext{
Fica permitido ao(s) autor(es) ou a terceiros a reprodução ou distribuição, em parte ou no todo, do material extraído dessa obra, de forma verbatim, adaptada ou remixada, bem como a criação ou produção a partir do conteúdo dessa obra, para fins não comerciais, desde que sejam atribuídos os devidos créditos à criação original, sob os termos da licença CC BY-NC 4.0.

EduComp'21, Abril 27-30, 2021, Jataí, Goiás, Brasil (On-line)

(C)2021 Copyright mantido pelo(s) autor(es). Direitos de publicação licenciados à Sociedade Brasileira de Computação (SBC)
}

desenvolvimento, produção e compartilhamento de conhecimentos, têm procurado se posicionar perante essa realidade e prover ações pertinentes às exigências dos sistemas educacionais e sociais da contemporaneidade. De acordo com essas exigências, os Parâmetros Curriculares Nacionais para o Ensino Médio $\left(\mathrm{PCNEM}^{1}\right)$ propõem a reorganização curricular em áreas de conhecimento de forma que facilite o desenvolvimento de conteúdos e fomente a interdisciplinaridade e a contextualização didática. A Base Nacional Comum Curricular $\left(\mathrm{BNCC}^{2}\right)$, por sua vez, elenca algumas competências que perpassam por todas etapas da Educação Básica com o objetivo de promover a construção de conhecimento, o desenvolvimento de habilidades e a formação de atitudes e valores.

$\mathrm{O}$ curso de extensão "Desenvolvimento de Competências Interdisciplinares no Currículo Escolar por Meio do Raciocínio Computacional" teve por objetivo apresentar processos do Raciocínio Computacional (RC) com vistas à descoberta de suas potencialidades para o desenvolvimento de competências disciplinares e interdisciplinares na educação básica, por meio de experimentações didáticas, discutindo questões conceituais de uso do RC para o desenvolvimento de habilidades e competências curriculares.

O curso foi ofertado para professores da educação básica de escolas públicas de Salvador/Bahia, com carga horária de 80 horas. Os encontros presenciais foram realizados nas dependências da Universidade Federal da Bahia (UFBA), com duração média diária de quatro horas. As atividades online foram realizadas por meio do ambiente virtual Moodle, com uso de videoaulas, infográficos, textos, fóruns e outros recursos multimidiáticos. Ao final, cada professor foi convidado a participar da autoavaliação e a produzir um texto sobre as experiências desse curso. Neste artigo relatamos a experiência da equipe executora com alguns relatos e reflexões dos professores participantes.

\footnotetext{
1 http://portal.mec.gov.br/seb/arquivos/pdf/blegais.pdf

2 http://basenacionalcomum.mec.gov.br
} 


\section{Formação de Professores para o Raciocínio Computacional}

Uma das competências do século XXI inclui a capacidade de raciocínio e resolução de problemas. Essa capacidade aponta para as competências de raciocínio crítico e pensamento sistêmico, identificação, formulação e resolução de problemas e criatividade e curiosidade intelectual [1]. Para além dessas competências, temse valorizado a capacidade de argumentação, de síntese e de compreensão de situações ou fenômenos complexos. Nesse sentido, os processos cognitivos do Raciocínio Computacional, inspirados na proposta de habilidades do Computational Thinking (Pensamento Computacional) [2], formam um conjunto de ferramentas mentais usado no raciocínio heurístico e que vão auxiliar na identificação e resolução de problemas do cotidiano.

Ferreira et al. [3] faz um questionamento acerca do uso dos termos Pensamento Computacional (PC) e Raciocínio Computacional (RC). Segundo os autores, o termo "pensamento" é uma "atividade da mente através da qual esta tematiza objetos ou toma decisões sobre a realização de uma ação.", enquanto "raciocínio" é uma "atividade do pensamento pela qual se procede a um encadeamento de juizos visando estabelecer a verdade ou a falsidade de algo" [14] apud [4].

Podemos assim enxergar uma diferenciação entre PC e RC, onde o PC busca utilizar ferramentas, competências e habilidades de computação na resolução de problemas. O RC expande esse conceito para além da resolução de problemas e aplicação de conceitos de computação com a finalidade de utilizar desses mesmos conceitos para desenvolvimento de habilidades múltiplas, como a argumentação e a leitura de situação e fenômenos complexos, auxiliando na tomada de decisões, exercitando a criatividade, criticidade e logicidade do indivíduo. Não apenas para resolver problemas, mas para desenvolver e descobrir novas habilidades e competências no indivíduo que o auxilie na sua vida em sociedade.

No curso proposto foram trabalhados os processos de decomposição/composição, reconhecimento de padrões, abstração e raciocínio algorítmico, por serem os quatro pilares do Raciocínio Computacional, assim como do Pensamento Computacional [5].

\subsection{Práticas de Formação de Professores}

As práticas de formação de professores são ações ao longo da vida profissional de um professor, seja por conta da construção identitária, seja pela necessidade constante de reflexão sobre a sua própria prática, as quais também desenvolvem-se em atividades de formação continuada.

Além disso, as mudanças sociais são frequentes, impactam e influenciam o ambiente escolar, exigindo que os currículos escolares e o professor estejam sempre atualizados. Santos et al. [6] afirmam que na sociedade atual o professor não pode se resumir em um mero transmissor de conhecimento. A sociedade mudou tornando os indivíduos mais complexos e exigindo que os professores também sejam. Diante disso, o investimento na formação continuada, na pesquisa e na experimentação de novas práticas lhes são úteis não somente para requalificação profissional, mas fundamentalmente para oferta de novos sentidos aos profissionais.

Segundo Tozetto, para dar conta das exigências que uma sala de aula impõe, o professor precisa de um saber múltiplo e polimorfo [7]. Logo, as formações, tanto inicial quanto continuada, devem ser menos fragmentadas e com integração entre aspectos conceituais e práticos.

Assim, o desafio está em construir conhecimento relacionando teoria e prática em conformidade com o mundo social que os indivíduos estão inseridos. Nesse contexto, entendemos que as formações continuadas se apresentam como ferramenta de estudo permanente a ser desenvolvido em todo percurso docente e contribuem para melhoria da prática, por conseguinte para educação [7].

Há na literatura trabalhos que relatam experiências em projetos que visam fomentar o uso do Pensamento Computacional ou do Raciocínio Computacional com alunos da educação básica. Em contrapartida, essas experiências não são tão comuns com professores.

Se o professor é uma figura essencial no ambiente escolar, por que não desenvolver o RC nesses professores?

Relatos de práticas de formação de professores no Brasil para o Pensamento Computacional ou para o Raciocínio Computacional ainda são tímidos. Dentre eles, destacam-se os trabalhos de Martinelli, Zaina e Sakata [8] e França et al. [9] no âmbito da formação inicial de professores. Todavia, encontram-se relatos e práticas em trabalhos internacionais, como em [10,11].

Destaca-se também o trabalho de Paz [12], que em seu relato de experiência sobre uma formação continuada utilizando o Pensamento Computacional, propõe a exploração colaborativa. Nessa abordagem, os professores compartilham experiências, relatam suas práticas e juntos traçam uma problemática em comum; essa problemática seria o elemento motivador para o uso do Pensamento Computacional.

De modo geral, atividades de formação continuada de professores consistem em considerar o contexto desses profissionais. A estrutura do curso precisa estar condizente com as atividades profissionais desenvolvidas pelos participantes, bem como com a realidade de cada indivíduo. Deve-se atentar ao estilo de vida, rotina, ritmo de aprendizagem e ambiente onde o mesmo desenvolve suas atividades. Normalmente em uma formação para professores de educação básica são encontrados contextos divergentes que vão desde a estrutura escolar até os níveis/séries escolares. Nesses cenários o compartilhamento de experiências, atividades interativas e o acolhimento de tutores/mentores são estratégias que vão resultar em melhor aproveitamento do curso e menor evasão.

\section{Metodologia}

Nesta seção apresentamos a proposta do curso em quatro momentos: ideação, organização do curso, seleção e sujeitos.

\subsection{Ideação}

O curso "Desenvolvimento de Competências Interdisciplinares no Currículo Escolar por Meio do Raciocínio Computacional" se categorizou como um curso de extensão para professores da Educação Básica promovido pelo ONDA DIGITAL - Grupo de Pesquisa e Extensão em Informática, Educação e Sociedade no âmbito do Programa de Ações Pedagógicas para Formação Docente em Computação (PROFCOMP).

Nessa ação, o objetivo foi estimular o desenvolvimento do raciocínio computacional e apresentar as suas potencialidades no/para o desenvolvimento de competências disciplinares e 
interdisciplinares na educação básica, de modo que o RC integrasse o arcabouço didático dos professores participantes.

A organização do curso foi coordenada pelo líder do grupo e coordenador do PROFCOMP, numa ação coletiva que envolveu pesquisadores, estudantes de graduação em Licenciatura em Computação, Sistemas de Informação e Bacharelado Interdisciplinar em Ciência e Tecnologia; estudantes de pósgraduação em Ciência da Computação e uma professora da Educação Profissional licenciada em Computação.

Para isso, foram realizadas reuniões semanais presenciais, registradas por meio de atas, ao longo de três meses. Nelas eram tomadas decisões tanto do desenvolvimento do curso, quanto da equipe.

O curso foi idealizado com carga horária de 80 horas, sendo 40 horas presenciais e 40 horas online. Os encontros presenciais ocorreram em sala de aula do Pavilhão de Aulas Professor Alceu Hiltner (PAF 2) do Campus de Ondina da UFBA, no turno noturno; e os encontros virtuais, por sua vez, ocorreram no ambiente virtual de aprendizagem Moodle-UFBA.

O planejamento didático do curso foi dividido em três módulos, com a proposta de:

- Módulo A: apresentar e discutir as habilidades do RC;

- Módulo B: elaborar planos de aula para intervenção didática;

- Módulo C: executar os planos elaborados, avaliando e relatando os seus resultados.

\subsection{Organização do Curso}

No módulo A, com a duração de 14 horas presenciais e 12 horas online, foram realizados três encontros de formação e um encontro adicional para ambientação com o Moodle. Os encontros desse módulo foram conduzidos com técnicas e metodologias ativas, tal como a computação desplugada, rodas de conversa, trabalhos em grupos, jogos. O principal objetivo desse momento foi apresentar os quatro processos basilares do Raciocínio Computacional, (decomposição/composição, reconhecimento de padrões, raciocínio algorítmico e abstração), além de discutir possibilidades de relacionar esses processos às práticas didáticas e pedagógicas dos professores.

O módulo B foi composto por 16 horas presenciais e 08 horas online, tendo quatro encontros presenciais. Por este curso ser o primeiro contato dos professores com o Raciocínio Computacional, o módulo que em princípio seria para planejamento didático, precisou ser revisto para reforçar os processos do Raciocínio Computacional apresentados no módulo anterior. Além da revisão, nesse módulo foi proposta a formação de pares com o objetivo de desenvolver um plano de aula para ser aplicado no período do módulo C. Nesse período também se instituiu um plano de mentoria, para que durante a realização do planejamento didático pelos professores, houvesse acompanhamento individualizado às suas dúvidas sobre o Raciocínio Computacional.

$\mathrm{O}$ módulo $\mathrm{C}$ foi composto por 10 horas presenciais, quatro horas online e 20 horas de atividade prática (realização das intervenções didáticas pelos professores). Além disso, houve carga horária adicional, ao final, de mais duas horas presenciais [optativas] para aquelas(es) professoras(es) interessadas(os) em revisão individualizada de sua sequência didática. Nesse módulo foi o momento de realizar ajustes finais nos planos de aula e sequências didáticas, aplicação das aulas pelos professores e respectivos feedbacks avaliativos. Esses feedbacks foram bidirecionais, ou seja, tanto da equipe de extensionistas para os professores, quanto dos professores para os extensionistas. Os feedbacks foram individualizados por meio do ambiente virtual Moodle e, também, por meio de uma roda de conversa.

O componente online do curso foi concebido com atividades e materiais complementares. Também havia espaços para dúvidas e diálogos livres entre os professores.

Para conclusão do curso, o(a) professor(a) deveria ter concluído $75 \%$ da carga horária do curso, considerando-se tanto as atividades presenciais, quanto as atividades online, às quais estavam associadas a um percentual de carga horária.

Ao final do curso, os professores concluintes apresentaram seus relatos de experiência no III Fórum Interdisciplinar sobre Formação Docente com Tecnologias ${ }^{3}$, evento acadêmico promovido desde 2014 pelo Grupo de Pesquisa e Extensão Onda Digital/UFBA no âmbito do PROFCOMP.

\subsection{Seleção}

A divulgação do curso foi realizada por meio de cards virtuais encaminhados por e-mail para diretores de cinco escolas públicas parceiras e nas redes sociais do Onda Digital. Contamos também com a divulgação para professores da rede estadual por meio de apoio da Secretaria da Educação do Estado da Bahia. Para seleção, 153 professores enviaram pedido de inscrição. Devido ao grande número de inscritos, ampliamos o número de vagas e 30 professores de diferentes áreas foram efetivamente matriculados.

Para a seleção foram utilizados os seguintes critérios:

- $\quad$ ser professor(a) de escola pública (caráter eliminatório);

- $\quad$ ser professor(a) de escola parceira do grupo de pesquisa e extensão anfitriã (caráter classificatório);

- ser professor(a) com condições de aplicar a sequência didática ao término do curso (caráter classificatório);

- $\quad$ ordem de inscrição (caráter classificatório);

- estar dentro da quantidade desejada de professoras(es) de cada área/disciplina (caráter classificatório).

Para atingir o último critério, no edital de seleção foi indicada a quantidade de vagas por cada disciplina escolar considerada, entre Artes, Biologia, Educação Física, Filosofia, Física, Geografia, História, Língua Portuguesa, Língua Estrangeira (Inglês/Espanhol), Matemática, Química, Sociologia e Informática.

\subsection{Sujeitos}

A equipe que executou a formação era composta por 4 doutores, 11 mestrandos, 8 graduandos e uma professora da educação básica licenciada em computação. Os doutores atuaram principalmente no momento de elaboração e criação do projeto, além de acompanharem as aplicações e em alguns momentos conduzirem os encontros. Os encontros foram conduzidos pelos mestrandos, que ajudavam também a desenvolver o material apresentado aos

3 http://www.forumondadigital.ufba.br 
professores. Os graduandos atuavam como tutores e mentores e davam apoio às aulas.

Dos 30 professores selecionados e matriculados, muitos tinham mais de uma formação e/ou atuavam em mais de uma disciplina da Educação Básica, conforme apresentado no Quadro 1.

Os professores aprovados efetivaram sua matrícula após apresentação de documentos e preenchimento dos termos de compromisso e de autorização de uso de imagem e voz.

Do conjunto de professores selecionados, 13\% atuavam prioritariamente nos Anos Iniciais do Ensino Fundamental; 37\% atuavam prioritariamente nos Anos Finais do Ensino Fundamental e $50 \%$ atuavam no Ensino Médio.

Quadro 1: Áreas de atuação dos professores e quantidade

\begin{tabular}{|l|l|}
\hline \multicolumn{1}{|c|}{ Área de atuação } & \multicolumn{1}{|c|}{ Quantidade } \\
\hline $\begin{array}{l}\text { Linguagens e suas } \\
\text { Tecnologias }\end{array}$ & $\begin{array}{l}12 \\
{[\text { sendo 03 de Língua Estrangeira, 03 de }} \\
\text { Educação Física e 06 de Lingua Portuguesa }]\end{array}$ \\
\hline Informática & 05 \\
\hline $\begin{array}{l}\text { Matemática e suas } \\
\text { Tecnologias }\end{array}$ & 05 \\
\hline $\begin{array}{l}\text { Ciências da Natureza e } \\
\text { suas Tecnologias }\end{array}$ & $\begin{array}{l}05 \\
{[\text { sendo 01 de Ciências, 02 de Química, 01 de }} \\
\text { Biologia e 01 de Física }]\end{array}$ \\
\hline $\begin{array}{l}\text { Ciências Humanas e } \\
\text { Sociais Aplicadas }\end{array}$ & $\begin{array}{l}\text { 15 } \\
{[\text { sendo 03 de História, 03 de Geografia, 05 }} \\
\text { de Filosofia e 04 de Sociologia }]\end{array}$ \\
\hline
\end{tabular}

Essa variedade foi interessante para termos compartilhamento de distintas visões e experiências entre os professores participantes.

\section{Execução do curso}

Embora houvesse planejamento prévio ao início do curso, à medida que os encontros ocorriam, algumas vezes foi necessário ajustar esse planejamento, para garantir que os professores suprissem suas lacunas de aprendizagem e tivessem seu aprendizado consolidado frente aos aspectos conceituais e didático-pedagógicos sobre o tema.

As formações foram realizadas por equipes compostas, geralmente, por dois ou três formadores e mais dois ou três tutores atuando em sala de aula. Enquanto os formadores apresentavam as temáticas e promoviam as discussões, os tutores estavam próximos aos professores para sanar as dúvidas que pudessem surgir e auxiliar na execução das atividades propostas.

Além da equipe de formação, nas salas havia também uma equipe responsável pela gravação de áudio e vídeo de todos os encontros, a fim de manter o registro dos encontros para fins de pesquisa.

A cada encontro eram apresentadas e discutidas as habilidades/processos cognitivos do Raciocínio Computacional e como estas poderiam ser inseridas no planejamento dos professores, seja na sua elaboração ou no ensino aos estudantes. No decorrer das aulas sempre ocorriam as práticas, quando os professores elaboravam planos de aulas ou recursos de aprendizagem para o desenvolvimento das habilidades do RC.
Nesse momento, além das práticas serem executadas em grupos de componentes curriculares afins, priorizando o debate e a discussão, com vistas ao aprendizado por pares, os professores sempre podiam contar com a parceria dos tutores para sanar dúvidas ou auxiliar na elaboração das propostas. Por estar em consonância com o desenvolvimento das Habilidades do Raciocínio Computacional, nas formações também foram abordadas as Metodologias Ativas, a Computação Desplugada e os jogos.

Foi feita uma curadoria minuciosa de slides, vídeos e artigos sobre os assuntos, entretanto também foi elaborado material instrucional pela equipe formadora para apoiar os professores. Para a elaboração desse material, foi levada em consideração a diversidade de componentes curriculares dos professores, assim, houve uma preocupação em pensar em exemplos e propor práticas que contemplassem os diferentes componentes curriculares.

Os tutores e mentores foram fundamentais para o desenvolvimento das atividades. Os tutores em sala auxiliavam nas dúvidas de seus tutorados, enquanto reforçavam o aprendizado dos temas abordados. Em momento posterior, foi a vez dos mentores atuarem auxiliando os professores na elaboração do plano de aula e relato de experiência, oferecendo momentos para mentoria tanto presencial, quanto no Moodle.

\section{Resultados}

A presente seção traz um breve resumo do que foi construído ao longo do curso por parte dos professores participantes. Na primeira subseção são apresentadas as práticas didáticas de alguns professores, seguidas da socialização dessas práticas e avaliação do curso.

Dos 20 professores concluintes, 15 aplicaram suas atividades em sala de aula e 14 apresentaram suas experiências no III Fórum Interdisciplinar sobre Formação Docente com Tecnologias. Todos os trabalhos passaram pela abordagem interdisciplinar com o objetivo de fomentar a ideia central do curso "Desenvolvimento de Competências Interdisciplinares no Currículo Escolar por Meio do Raciocínio Computacional”. O Quadro 2 apresenta um resumo dos professores e seus relatos de experiência.

Utilizaremos na discussão deste trabalho os relatos de quatro professores participantes que serão indicados por meio de numeração em romanos e sem distinção de gênero (Professor I, Professor II, Professor III, Professor IV). Os professores I, II e IV aplicaram as aulas com estudantes do Ensino Médio (Regular e Profissional). O professor III aplicou com estudantes do $7^{\circ}$ ano do Ensino Fundamental.

Nas propostas didáticas, o(a) professor(a) deveria utilizar pelo menos um dos processos do Raciocínio Computacional estudados no curso: abstração, decomposição/composição, reconhecimento de padrões ou raciocínio algorítmico.

\subsection{Relatos dos Professores}

O Professor I destacou a habilidade de reconhecimento de padrões atuando na disciplina "Projeto de Aprendizagem em Mídias", em que o professor contou com a parceria de professores de outras disciplinas, como Língua Portuguesa, Biologia e Artes, na realização de um projeto nomeado \#TONOBARROCO. A ideia do projeto era utilizar a criptografia digital com o QRCode para a leitura de um folder interdisciplinar sobre o Barroco. A partir do estudo de vários tipos de cifragem e atividades práticas, os professores do projeto \#TONOBARROCO trabalharam com os 
estudantes uma diversidade de padrões na escrita, e mostraram que cada técnica de criptografia exige um padrão diferente.

O Professor II, de Língua Portuguesa e Redação, afirma em seu relato, que utilizou todos os processos do Raciocínio Computacional estudados para resolver "senão o maior, um dos problemas dos seres humanos: a comunicação entre interlocutores". Dois processos foram mais evidentes: raciocinio algorítmico e reconhecimento de padrões. Com o conteúdo de "Argumentos: conceitos e tipos", o professor criou uma sequência algorítmica para apresentar a definição de "argumento" para a turma. Dando continuidade, trabalhou um texto com os alunos com a finalidade de identificar os tipos de argumentos, suas similaridades e diferenças no texto e falas (reconhecimento de padrões).

Já o Professor III, que lecionava a disciplina de História, fez uso da abstração e do reconhecimento de padrões para discutir o conteúdo "principais características do Feudalismo e Mercantilismo".

A abstração foi utilizada como estratégia para delimitar os eventos a serem estudados, visto que se tratava de um conteúdo amplo para alunos de faixa etária entre 10 e 12 anos. Segundo o professor, "A abstração, como estratégia didática, está no esforço em apresentar as principais características do Feudalismo e do Mercantilismo, como também as medidas tomadas pelos reis que resultaram no fortalecimento das suas monarquias e constituição dos estados-modernos. Sem esquecer que se está frente a um semnúmero de acontecimentos, datas, feitos e grupos que também, sob outras perspectivas, integram a História do evento estudado".

O reconhecimento de padrões foi usado para ajudar a definir o Feudalismo e o Mercantilismo a partir de padrões estabelecidos historicamente. O professor relata que "Os padrões existentes, por exemplo, nas medidas tomadas pelos monarcas, com o intuito de fortalecer suas monarquias, não esgotam os elementos constitutivos das tramas históricas que derivaram estes acontecimentos. Mas, permite que os estudantes aprendam uma série de informações básicas acerca dos eventos estudados. Possibilitando que os compreendam, distingam e comparem".

O Quadro 2 apresenta um resumo dos títulos dos relatos de experiência, disciplinas e série de aplicação dos planos elaborados. Esses relatos serão condensados e disponibilizados em livro no formato eletrônico $(e-b o o k)$.

Quadro 2: Resumo dos relatos dos professores concluintes

\begin{tabular}{|c|c|c|c|}
\hline Nome & Disciplina & Série/Nível & Título do Relato de Experiência \\
\hline Professor I & $\begin{array}{l}\text { Projeto de Aprendizagem } \\
\text { em Mídias }\end{array}$ & $1^{\circ}$ - Médio regular & $\begin{array}{l}\text { A Expertise da Realidade Aumentada na Escola de Ensino Médio Interagindo com o } \\
\text { Projeto Interdisciplinar \#TONOBARROCO. }\end{array}$ \\
\hline Professor II & Redação & Médio técnico & $\begin{array}{l}\text { O Raciocínio Computacional e a disciplina Redação - análise crítica de um tecer entre } \\
\text { habilidades e recursos. }\end{array}$ \\
\hline Professor III & História & $7^{\circ}$ Fundamental II & O uso do Raciocínio Computacional interdisciplinar no Ensino de História. \\
\hline Professor IV & Língua Inglesa & Médio Técnico & $\begin{array}{l}\text { O desenvolvimento do raciocínio algorítmico no ensino de Língua Inglesa Instrumental, } \\
\text { no curso de Meio Ambiente: uma experiência com o Simple Past. }\end{array}$ \\
\hline Professor V & Língua Portuguesa & $1^{\circ}$ Médio regular & Algumas habilidades do raciocínio computacional. \\
\hline Professor VI & Ciências Naturais & $6^{\circ}$ Fundamental II & $\begin{array}{l}\text { Experiência Prática Interdisciplinar das Habilidades do Raciocínio Computacional em } \\
\text { Aula de Ciências Naturais }\end{array}$ \\
\hline $\begin{array}{l}\text { Professor } \\
\text { VII }\end{array}$ & $\begin{array}{l}\text { Fundamento e Arquitetura } \\
\text { de Computadores }\end{array}$ & $1^{\circ}$ Médio técnico & $\begin{array}{l}\text { Experiência Prática Interdisciplinar do Raciocínio Computacional em Competências } \\
\text { Interdisciplinares no currículo escolar da Educação Básica no Ensino Profissional. }\end{array}$ \\
\hline $\begin{array}{l}\text { Professor } \\
\text { VIII }\end{array}$ & Matemática & $2^{\circ}$ Médio técnico & Inteligência computacional aplicada aos alunos da turma $2^{\circ}$ ano de informática $\mathrm{B}$. \\
\hline Professor IX & Física & $2^{\circ}$ Médio regular & $\begin{array}{l}\text { Ensino de Óptica amparado pelo raciocínio computacional: Uma experiência com uma } \\
\text { turma de } 2^{\circ} \text { ano do ensino médio de uma escola pública estadual na cidade de Salvador- } \\
\text { Ba. }\end{array}$ \\
\hline Professor X & Química & Proeja & $\begin{array}{l}\text { A utilização do Raciocínio Computacional como ferramenta metodológica para o ensino } \\
\text { de reações inorgânicas em uma turma de PROEJA de um centro de educação profissional } \\
\text { na cidade de Salvador - BA. }\end{array}$ \\
\hline Professor XI & História & $5^{\circ} / 6^{\circ}$ Fundamental II & Raciocínio Computacional: Sua introdução no ensino de História. \\
\hline $\begin{array}{l}\text { Professor } \\
\quad \text { XII }\end{array}$ & $\begin{array}{l}\text { Gestão e } \\
\text { Empreendedorismo }\end{array}$ & $4^{\circ}$ Médio técnico & Raciocínio Computacional na educação profissional \\
\hline $\begin{array}{l}\text { Professor } \\
\text { XIII }\end{array}$ & Matemática aplicada & $\begin{array}{l}\text { Módulo II - Médio } \\
\text { técnico }\end{array}$ & $\begin{array}{l}\text { Equivalência lógica: uma atividade envolvendo habilidades do Raciocínio } \\
\text { Computacional com alunos de um curso de Educação Profissional na construção de um } \\
\text { jogo. }\end{array}$ \\
\hline $\begin{array}{l}\text { Professor } \\
\text { XIV }\end{array}$ & Língua Portuguesa & $9^{\circ}$ Fundamental II & Experiência pedagógica utilizando as habilidades do raciocínio computacional. \\
\hline $\begin{array}{l}\text { Professor } \\
\quad \mathrm{XV}\end{array}$ & Educação física & $2^{\circ} / 3^{\circ}$ médio regular & Habilidades Computacionais e a Práxis Pedagógica da Educação Física \\
\hline
\end{tabular}


O Professor IV, além de utilizar a abstração e o reconhecimento de padrões, fez uso também do processo de decomposição/composição.

A decomposição/composição, segundo o próprio participante, contribuiu com o aprendizado do conteúdo "Simple Past", na disciplina de língua inglesa. O professor atuou com alunos na faixa etária entre 15 e 25 anos e ratifica que quebrar um problema em partes menores ajuda no entendimento e resolução do mesmo, indicando que "Dessa forma, durante a construção do mapa conceitual, os estudantes foram 'quebrando' o conteúdo sobre o Simple Past, utilizaram as regras dos verbos terminados em -ed, ied ou -d e forneceram exemplos. [parafraseando [13]] 'Quando um problema não está decomposto, sua resolução é muito mais difícil. Por exemplo, para entender o funcionamento de uma bicicleta, é mais fácil através do desmembramento de suas partes'. Então, o mapa conceitual contribuiu para o uso do processo decomposição/composição e o conteúdo abordado de Língua Inglesa" (grifo nosso). O mapa conceitual foi construído na lousa da sala de forma colaborativa pelos 11 alunos participantes da intervenção.

A aplicação das aulas também enfrentou muitos desafios e dificuldades. Essas dificuldades vão desde a infraestrutura escolar até o baixo nível de conhecimento dos alunos em relação aos conteúdos, sendo necessário, nesses casos, que toda intervenção viesse precedida de uma revisão.

Além disso, a resistência dos alunos com o novo, a evasão e a inconsistência de horários também foram citados como elementos dificultadores, resultando em suspensão das intervenções pelo professor; sendo necessário, por algumas vezes, replanejamento. Contudo, segundo o professor, houve rendimento em todas as suas intervenções.

Resumidamente, todos os professores que aplicaram suas atividades em sala de aula pontuaram o uso do RC como uma estratégia relevante no ensino de conteúdos para educação básica. Para eles, a ideia de utilizar as habilidades trabalhadas no curso para ensinar, auxilia na compreensão do conteúdo e desmistifica o uso restrito de equipamentos tecnológicos quando se trata de ferramentas que tenham a computação como base. É importante lembrar que muitos professores assinalaram em seus relatos o prazer de inovar suas práticas didáticas, e por conseguinte despertar o prazer também em seus alunos. Essas inovações nada mais são que a inserção de novas práticas metodológicas no currículo escolar, muitas delas proporcionadas por meio das formações continuadas.

\subsection{Socialização das Práticas}

Os professores participantes do curso tiveram a oportunidade de socializar os produtos gerados e experiências vivenciadas, durante a realização do III Fórum Interdisciplinar sobre Formação Docente com Tecnologias. O evento gratuito e aberto ao público teve a participação de cerca de 100 pessoas e possibilitou aos professores, além de conhecer os trabalhos desenvolvidos pelos seus colegas de curso, apresentar seu trabalho e receber feedback de outros professores e pesquisadores, contribuindo para futuras práticas e ações que envolvam o desenvolvimento de competências disciplinares ou interdisciplinares por meio do Raciocínio Computacional.

\footnotetext{
$4 \underline{\text { http://youtube.com/c/ProgramaOndaDigital }}$
}

De modo mais geral, esse evento tem como objetivo ampliar o debate e a pesquisa sobre novas formas de produzir e utilizar as Tecnologias Digitais de Informação e Comunicação (TDIC) com propósitos educacionais, visando apoiar processos individuais e coletivos de aprendizagem e construção de conhecimento.

Desde sua concepção, em 2014, o evento conta com o apoio da Pró-reitoria de Extensão da UFBA, da gestão do Instituto de Matemática e Estatística da UFBA e do Colegiado do curso de Licenciatura em Computação. Em 2017, na sua terceira edição, o tema foi "A importância do Raciocínio Computacional na Escola". O evento integrou a programação da Semana Nacional de Ciência e Tecnologia, financiada por meio de chamada pública do Conselho Nacional de Desenvolvimento Científico e Tecnológico (CNPq) e Ministério da Ciência, Tecnologia e Inovações (MCTIC).

Como parte das atividades do curso "Desenvolvimento de Competências Interdisciplinares no Currículo Escolar por Meio do Raciocínio Computacional", os professores que concluíram os seus planejamentos didáticos com uso do Raciocínio Computacional (plano de aula e sequência didática) e realizaram a aula planejada, apresentaram relatos desenvolvidos com o apoio de seus tutores relatando a experiência vivenciada em sala de aula, e refletindo acerca das potencialidades do Raciocínio Computacional em suas disciplinas, dificuldades e desafios. Esses relatos foram apresentados em sessão técnica desse evento.

A revisão dos resumos foi realizada pela equipe do projeto e fundamental apoio dos tutores. Assim, os resumos foram submetidos na plataforma do evento e integraram a programação das comunicações orais. Foram organizados blocos de 30 minutos de apresentação com três trabalhos cada, seguidos de 10 minutos de discussão. Quatorze professores participaram desse momento e receberam certificado de apresentação de trabalho. As apresentações orais estão disponíveis em vídeo no canal do Youtube do Onda Digital ${ }^{4}$.

\subsection{Avaliação do Curso}

Ao final do curso, os professores concluintes foram convidados a responder um questionário de avaliação. $\mathrm{O}$ objetivo do questionário foi avaliar o curso e aperfeiçoar versões futuras.

O questionário foi composto por oito questões em que os professores puderam responder de forma online e apresentar sua autoavaliação, críticas e sugestões em relação ao curso. As questões a serem respondidas concentraram-se em conceituar o desempenho dos instrutores, tutores e mentores, e avaliar a atuação individual de cada professor.

Os professores apontaram os seguintes pontos de melhoria para o curso: atendimento online; tempo de duração do curso; e suas etapas.

O atendimento online foi realizado por meio do Moodle (chats e fóruns). Os professores sugeriram que fossem utilizados outros aplicativos de mensagens rápidas, como WhatsApp e Facebook. A maioria dos professores indicou que encontraram dificuldade na utilização do Moodle. Isso já havia sido percebido pela equipe executora (grupo de extensionistas).

Quanto ao período de duração do curso, os professores demonstraram insatisfação quanto ao tempo destinado para conclusão do curso. Eles(as) indicaram haver necessidade de mais tempo para compreender o conteúdo ainda novo para eles(as). Também gostaria de mais tempo para aplicar em sala de aula o 
planejamento realizado, além de mais encontros presenciais de formação, principalmente na etapa final, independente do auxílio de tutores e mentores.

Como o curso ocorreu no segundo semestre do ano, não havia tempo hábil para execução de mais de um plano de aula pelos professores, que usaram as últimas aulas da última unidade letiva para suas intervenções.

Além dos questionamentos apresentados, procuramos saber sobre o alcance obtido nas aplicações/intervenções, o que eles(as) acharam do Raciocínio Computacional e das suas possibilidades.

O Professor II afirmou que "a associação do RC ao processo de resolução de problemas potencializa esta correlação interdisciplinar, inclusive com a disciplina Redação, haja vista que uma das competências para desenvolvimento da escrita consiste em resolver, senão o maior, um dos problemas dos seres humanos: a comunicação entre interlocutores".

O Professor I pontuou que utilizou as habilidades do RC ainda na fase de planejamento: "As habilidades e competências do Raciocínio Computacional que foram mais evidentes durante o planejamento e execução do projeto (...)".

Por sua vez, o professor IV considerou ser “(...) possível desenvolver as habilidades do Raciocínio Computacional em outros conteúdos de Língua Inglesa, com isso espera-se tornar as aulas mais dinâmicas, interessantes e significativas para os estudantes. Utilizar o raciocínio computacional de forma interdisciplinar trouxe a possibilidade de inovação nas disciplinas curriculares. Por meio do desenvolvimento de habilidades, foi possivel trabalhar os conteúdos de forma prazerosa, cativando os discentes para a aprendizagem que é uma condição primordial para interação em sociedade".

Outros professores participantes destacaram que as habilidades do Raciocínio Computacional estimulam a ressignificação de práticas pedagógicas, contribuem na aprendizagem e tornam o ensino mais dinâmico e menos “engessado". De acordo com o professor XI, "(...) após aplicação da intervenção utilizando as habilidades do Raciocínio Computacional, ficou notório que essa ferramenta incorporada ao ensino tradicional torna a aprendizagem mais significativa e elas vêm abrindo caminho para uma nova realidade na vida do ser humano por um todo".

De todo modo, as observações recebidas foram úteis para edições futuras do curso e para se ter uma ideia, não conclusiva, mas elucidativa, de como os professores percebem as potencialidades do Raciocínio Computacional para além da sala de aula, além das necessidades formativas, considerando que se trata de novos conhecimentos e, fundamentalmente, novas possibilidades didático-pedagógicas.

\section{Reflexões e Considerações Finais}

Diante dos relatos, observamos que os professores pensaram para além da sala de aula, isto significa dizer que o RC pode e deve fazer parte do nosso cotidiano escolar, auxiliando na resolução de problemas tanto profissionais quanto pessoais.

Da mesma maneira, entendemos que o curso foi exitoso, atingindo o objetivo a que se propunha. Todos os envolvidos, professores e equipe formadora, ao término do curso conseguem inserir as habilidades do RC no seu cotidiano e na sua prática educativa.
Apesar do sentimento de objetivo alcançado, por parte de todos, nas avaliações foram verificadas algumas falhas quanto ao tempo destinado ao curso e as ferramentas digitais utilizadas. No entanto, após avaliação dos professores e autoavaliação da equipe formadora, já foram estudadas e planejadas novas ações para, nas próximas formações, proporcionar mais estímulos à criticidade, à logicidade e à criatividade dos participantes por meio do desenvolvimento das habilidades do Raciocínio Computacional.

Este texto não se trata de um artigo de pesquisa, portanto, decidimos focalizar em alguns relatos e escrever em primeira pessoa. Em trabalhos futuros, pretendemos explorar os dados coletados por meio de gravações de áudio, de vídeos, atividades, fóruns, relatos e questionários.

\section{AGRADECIMENTOS}

A realização desta ação foi possível graças ao empenho e dedicação de um conjunto de participantes que mencionamos aqui e estendemos o mérito deste trabalho, para além dos autores deste artigo: Prof. Dr. Adolfo Tanzi Neto, Profa. Dra. Débora Abdalla Santos, Prof. Dr. Marlo Vieira dos Santos e Souza, Carlos Alexandre Nascimento, Emilayne Feitosa Corlett, Fábio Correia Rezende, Rosimeire Teixeira Simões, Filipe Adeodato Garrido, Beatriz Brito Rêgo, Josualdo Junior Dias da Silva, Conceição Aparecida Gonçalves Tavares, Ranansamir Sousa da Silva, Ila Mascarenhas Muniz, Luiz Fernando de Paiva, Ana Carolina Cerqueira Ferreira, Willian Fabian Machado Vera, Thacio Kevin da Silva Miranda Oliveira, Hugo Marvin Dourado e Ricardo Henrique Santana Gomes.

Estendemos nossos agradecimentos à Pró-Reitoria de Extensão da UFBA e ao Conselho Nacional de Desenvolvimento Científico e Tecnológico - CNPq, pela Bolsa de Produtividade em Pesquisa outorgada ao primeiro autor.

\section{REFERÊNCIAS}

[1] Aldo M. Filho. 2015. Competências de aprendizagem do século XXI: como desenvolver atividades nas disciplinas do parâmetro curricular nacional (PCN) com o uso do Scratch? In Anais do Educere - XII Congresso Nacional de Educação.

[2] Jeannette M. Wing. 2006. Computational thinking. Communications of the ACM 49.3 33-35.

[3] Ana C. Ferreira, André Melhor, Jandiaci Barreto, Luiz F. de Paiva, Ecivaldo Matos. 2015. Experiência prática interdisciplinar do raciocínio computacional em atividades de computação desplugada na educação básica. In Anais do Workshop de Informática na Escola. Vol. 21, No. 1, p. 256.

[4] Luiz F. de Paiva, Ana C. Ferreira, Caio Rocha, Jandiaci Barreto, André Melhor, Randerson Lopes, Ecivaldo Matos. 2015. Uma experiência piloto de integração curricular do raciocínio computacional na educação básica. In Anais dos Workshops do Congresso Brasileiro de Informática na Educação. Vol. 4, No. 1, p. 1300 .

[5] Christian Brackmann, Dante Barone, Ana Casall, Rafael Boucinha, Susana Muñoz-Hernandez. 2016. Computational Thinking: Panorama of the Americas. Disponível https://www.researchgate.net/publication/310807767_Computational_thinking Panorama_of the_Americas. Acesso em: Out 2020. 978-1-5090-45969/16/\$31.00 (C2016 IEEE.

[6] Camille A. de O. Santos, Carla C. de F. Silva, Ana B. C. M. de Oliveira. 2017. Formação de professores: o desafio da prática. In Anais do Edcuere - XIII Congresso Nacional de Educação.

[7] Susana S. Tozetto. 2017. Docência e formação continuada. In Anais do Edcuere - XIII Congresso Nacional de Educação, IV Seminário Internacional de Representações Sociais, Subjetividade e Educação - SIRSSE, Curitiba - PR. p. 24537-24549. Disponível em: https://educere.bruc.com.br/arquivo/pdf2017/23503_13633.pdf. Acesso em: 23 out. 2020.

[8] Suéllen R. Martinelli, Luciana M. Zaina, Tiemi C. Sakata. Linking Computational Thinking and BNCC in Primary School: a qualitative study on the 
perspective of teachers. Journal on Computational Thinking (JCThink), v. 3, p. 19-33, 2020.

[9] Rozelma França, Victor Ferreira, Luma de Almeida e Haroldo do Amaral. 2014 A disseminação do pensamento computacional na educação básica: lições aprendidas com experiências de licenciandos em computação. In Anais do XXII Workshop sobre Educação em Computação, July 28, 2014, Brasília, Brasil. SBC, Porto Alegre, Brasil, 219-228.

[10] Michael Lodi. 2017. Growth Mindset in Computational Thinking Teaching and Teacher Training. Proceedings of the 2017 ACM Conference on International Computing Education Research. Association for Computing Machinery, New York, NY, USA, 281-282

[11] Rania Hodhod, Shamim Khan, Yesem Kurt-Peker, and Lydia Ray. 2016. Training Teachers to Integrate Computational Thinking into K-12 Teaching. In Proceedings of the 47th ACM Technical Symposium on Computing Science Education (SIGCSE '16). Association for Computing Machinery, New York, NY, USA, $156-157$.

[12] Louise A. S. do C. Paz. 2017. O Pensamento Computacional e a formação continuada de professores: uma experiência com as TICs. RPGE-Revista on-line de Política e Gestão Educacional, Araraquara, v.21, n. esp.3, p. 1655-1667, dez.

[13] Christian Brackmann. 2017. Desenvolvimento do Pensamento Computacional através de Atividades Desplugadas na Educação Básica. 226f. Tese (Doutorado em Informática na Educação). Centro Interdisciplinar de Novas Tecnologias na Educação. Universidade Federal do Rio Grande do Sul, RS.

[14] Japiassú, H.; Marcondes, D. (1993). Dicionário básico de filosofia. Zahar.Rio de Janeiro. 